\title{
Os novos movimentos de direita no Brasil e o discurso partidário: ambivalências e contradições
}

\author{
Letícia Baron $^{1}$
}

\section{Resumo}

Valendo-se das ferramentas da teoria do discurso de Laclau e Mouffe, o objetivo do presente trabalho é analisar os sentidos discursivos presentes nas postagens dos movimentos Revoltados Online, Movimento Brasil Livre, Vem pra Rua e Endireita Brasil que explicitem as visões dos movimentos sobre os partidos políticos no Brasil no período do impeachment da exPresidente Dilma Rousseff. Nesse sentido, em um primeiro momento, o artigo se propôs a fazer uma revisão na literatura sobre a identificação partidária no Brasil pós-redemocratização para, posteriormente, identificar a crítica dos movimentos sobre a capacidade de representação dos partidos políticos. Considerando que a rede social Facebook assume centralidade para a difusão do discurso da direita, foram analisadas as 5.266 postagens dos quatro movimentos na rede social no período em que tramitou o processo de impeachment. Dessas, 1.858 versam sobre o papel dos partidos políticos na democracia. $O$ artigo conclui que os movimentos concentram a maior parte de suas críticas ao Partido dos Trabalhadores, bem como buscam meios de renovar a política com a inclusão de novos atores ideologicamente orientados para a direita.

Palavras-chave: Novos movimentos; Direita no Brasil; Impeachment; Antipartidarismo; Teoria do discurso.

\section{Abstract}

Based on Laclau's Theory of Discourse, this study seeks to verify the meanings atributted to anti-party feelings established between the movements Endireita Brasil, Brasil Livre, Vem pra Rua and Revoltados Online when the impeachment of President Dilma Rousseff was in progress. In this sense, the articule's first part review party's literature in Brazil after democratization to, after, identify the movements critics about the party's hability of representation. Considering the growing importance of Facebook in right's speech diffusion, the autor analised 5.266 four movement's post

\footnotetext{
${ }^{1}$ Doutoranda em Ciência Política pela Universidade Federal de Pelotas. O presente trabalho foi realizado com apoio da Coordenação de Aperfeiçoamento de Pessoal de Nível Superior Brasil (CAPES) - Código de Financiamento 001.
} 


\begin{abstract}
when impeachment was in progress. From these, 1.858 posts talks about the party's function in democracy. The article concludes that the most considerable critics are directed to Workers Party. The movements are worry, as well, in increase de right's ideology influence by the new actors' introduction.

Key-words: New Movements; Brasil's right; Impeachment, Anti-party, Discourse Theory.
\end{abstract}

\title{
Introdução
}

A observação dos partidos políticos na democracia contemporânea tem demonstrado que eles, especialmente aqueles caracterizados como de massas, têm sofrido as consequências de um processo de esvaziamento interno, dada a dificuldade de mobilizar a militância para as atividades corriqueiras da organização (Mair, 2003; Van Biezen, 2012; Inglehart, 1977; Norris, 1999). Pensando a democracia a partir da observação dos países europeus, concluiu-se que os partidos de massas e as condições que os deram origem estão desaparecendo (Mair, 2003; Van Biezen, 2012), abrindo uma nova - e extensa - agenda de pesquisa que visa discutir o distanciamento dos partidos políticos e do eleitorado. O fenômeno já é observado nos Estados Unidos (Putnam, 2003; Dalton, 2013) e na Europa (Mair e Van Biezen, 2001; Mair, 2000; 2003).

Os resultados das pesquisas vêm a demonstrar que essa nova configuração pode trazer efeitos deletérios à democracia, visto que a redução do engajamento partidário pode conduzir à diminuição do comparecimento eleitoral, à fluidez na escolha dos representantes e desenvolver um sentimento de ceticismo com relação aos processos e instituições representativas (Putnam, 2002). A confluência desses fatores ocasionaria uma crise de legitimidade partidária, o qual poderia gerar o questionamento da democracia enquanto ideal a ser perseguido (Norris, 1999).

Importando a preocupação dos cientistas políticos europeus e norteamericanos à realidade latino-americana, o cenário que se expõe fica ainda mais confuso, visto que se tratam de democracias ainda muito jovens e com resquícios da interferência de governos autoritários (Gimenes, 2014). A adesão democrática de cidadãos com baixa tradição tende a ser mais frágil, o que permite que os pesquisadores prevejam efeitos deletérios a desafeição partidária, aventando 
hipóteses de efeitos desestabilizadores (Ribeiro, 2011; Torcal e Monteiro, 2006). Os governos militares produziram gerações de cidadãos apáticos politicamente, acostumados a baixos níveis de participação política e afeiçoados a grandes líderes personalistas (Baquero, 2000; Alcántara Saez e Freidenberg, 2002). Neste contexto, no período da redemocratização, os partidos políticos ressurgiram como atores políticos importantes, porém não se consolidaram enquanto instituições efetivas de mediação política (Baquero, 2000).

O modelo de democracia instituído na América Latina já vem enfrentando, desde o início do século, uma crise que também envolve os partidos políticos (Baquero, 2000). Esses não aparentam apresentar coerência institucional, visto que não raro abandonam seu perfil ideológico para se tornar máquinas eleitorais que, objetivando acumular postos na estrutura governamental, passaram a adotar posturas centristas, tipo catch all (ibidem).

A tendência dos partidos políticos de fazerem composição e condicionarem a sua oposição com vis a manter a governabilidade (mesmo que isso contrarie o seu programa) fez com que segmentos da sociedade civil alinhados com a ideologia liberal questionassem os posicionamentos e políticas públicas aprovadas ao longo do governo petista no Brasil (Gimenez e Borba, 2016). O discurso oposicionista surge no contexto das manifestações ainda em 2007, quando o movimento CANSEI promove pequenas manifestações em São Paulo (Tatagiba, Trindade e Teixeira, 2015). Ele ressurge nas jornadas de 2013 e toma contornos mais fortes nas grandes manifestações ocorridas ao longo dos anos de 2015 (idem) e 2016.

Nesse sentido, considerando-se o teor de tais discursos, se coloca como uma importante agenda de pesquisa para a ciência política no Brasil a compreensão sobre a influência dos partidos políticos na consolidação (ou não) da democracia representativa. O presente trabalho tem por objetivo contribuir - ainda que timidamente - com esse debate, mediante a análise dos sentidos que compuseram os discursos dos movimentos que assumiram o protagonismo das grandes manifestações que aconteceram em 2015 e 2016 - a saber, o Revoltados OnLine, o Vem pra Rua, o Movimento Endireita Brasil e o Movimento Brasil Livre - sobre o sistema partidário 
brasileiro. Busca-se esclarecer se, no período em que foi processada e julgada a então Presidente Dilma, as críticas tecidas se dirigiram a uma parcela da ou à classe política como um todo.

A fim de responder à pergunta, serão analisados os discursos dos movimentos na rede social Facebook no período de dezembro de 2015 a agosto de $2016^{2}$, bem como os materiais disponíveis em seus sites oficiais. O período de análise corresponde aos meses em que foi recebido, processado e julgado o impeachment da Presidenta Dilma Rousseff.

$\mathrm{O}$ artigo se divide em quatro partes distintas. A primeira delas vem a debater sobre a construção de uma identidade partidária no Brasil. A segunda parte contextualiza o surgimento dos movimentos estudados e busca elucidar suas principais demandas, aproximando-os da ideologia mais à direita do espectro político. A terceira parte tem por objetivo demonstrar a construção metodológica do trabalho, levando em consideração as ferramentas desenvolvidas por Laclau e Mouffe (2015). Por fim, a quarta parte mostra a construção discursiva realizada pelos movimentos em torno da temática dos partidos políticos, relacionando tais resultados com a literatura sobre identificação partidária no Brasil.

\section{Partidos Políticos e identificação partidária na Nova República}

Quando analisa os partidos políticos na Europa, Mair (2003) observa que houve uma mudança no padrão de ações e prioridades partidárias, sendo que a atenção desses se voltou muito mais às necessidades de organização do Estado do que necessariamente dar uma resposta satisfatória às demandas populares. Preconizando o fim dos partidos de massas, ele diagnostica uma crescente apatia por parte dos

\footnotetext{
${ }^{2}$ Optou-se por realizar a análise das postagens dos movimentos na rede social Facebook (em detrimento de outras, como, por exemplo, Twitter ou Instagram) porque ela se consolidou como a principal ferramenta de comunicação entre os movimentos e seus seguidores, assumindo especial importância no período analisado. A fim de comprovar tal afirmação, destaca-se o seguinte trecho da instrução presente no Manual do MBL para Filiais Municipais: "a página de Facebook é um importante instrumento de divulgação das ideias do movimento. Os efeitos de uma vitória neste campo de batalha serão sentidos em todos os outros" (MBL, 2015, p. 26).
} 
cidadãos, que inclusive se reverte em baixa participação no processo eleitoral e nas dinâmicas partidárias.

Isso decorre de uma transformação na própria função dos partidos políticos, que reduziram sua importância nas ações representativas e focaram nas ações procedimentais, destinadas a composição de governança no âmbito do Estado (Van Biezen, 2014). Essas mudanças influem na identificação partidária dos cidadãos, já que as necessidades de composição de órgãos no governo atenuam as diferenças entre as diferentes legendas (Mair, 2003). Nesse sentido, a reconfiguração da ideia de representação se coloca como um grande desafio às democracias contemporâneas, uma vez que a estabilidade social e política indispensáveis à maturação da política nas democracias liberais se encontra progressivamente ameaçada como resultado da crescente individualização, globalização e mediação nas democracias modernas, assim como no processo de horizontalização das relações de autoridade (Van Biezen, 2014).

O diagnóstico do Mair e Van Biezen se dá a partir da análise de democracias consolidadas, nas quais os partidos políticos possuem uma longa tradição e os cidadãos foram educados a partir de uma lógica eleitoral constante. Na América Latina, a mudança no perfil dos partidos políticos vem acompanhada da influência de variáveis locais, que dizem respeito à forma tradicional de se fazer política e ao baixo experimentalismo democrático, dada as constantes interrupções ocasionadas pela instauração de governos autoritários.

No Brasil, a trajetória do sistema partidário é caracterizada por muita instabilidade, o que influi sobre a capacidade do eleitor brasileiro se identificar com a política por si e com um partido político em específico (Gimenes, 2015). Os brasileiros convivem com uma pluralidade partidária desde 1979, com a promulgação da Lei 6.767. Anos mais tarde, o fim do ciclo militar também trouxe uma série de medidas democratizantes, como a concessão de votos aos analfabetos, a revogação da cassação de partidos políticos pelo governo militar, eleições diretas e a promulgação de uma nova constituição (Nicolau, 2012).

Isso não quer dizer, contudo, que a política se tornou acessível à grande maioria da população. Os estudos sobre cultura política apontam para a existência de uma 
forte presença de personalismo (Rodrigues, 2002), de desconfiança nos partidos políticos (Baquero e Linhares, 2010), de alta volatilidade eleitoral (Braga, 2006), da elevada migração partidária (Melo, 2014), da efemeridade dos partidos políticos no jogo eleitoral (Mainwaring, 2001), de multiplicação de legendas (Carreirão e Kinzo, 2004), vinculados a um alto déficit de cidadania, que faz com que o eleitor brasileiro apresente um baixo nível de identificação partidária.

Além disso, o sistema de composição de maiorias no Brasil é complexo, favorecendo a composição entre forças partidárias que deveriam estar em lados ideológicos opostos (Miguel e Machado, 2010), o que contribui para a dificuldade dos eleitores se afeiçoarem a partidos políticos.

Em alguma medida, o fenômeno descrito por Mair também é observado no Brasil, visto que há uma tendência à institucionalização do sistema partidário nacional, caracterizado pela volatilidade eleitoral e fragmentação partidária, além de não existir estabilidade nas coligações partidárias (Carreirão, 2014). Contudo, diferentemente do contexto europeu, as legendas são ainda recentes e não lograram êxito em se enraizar junto ao eleitorado, o que fragiliza a expectativa que os eleitores mantém com relação a representação (Carneiro e Moisés, 2015). Isso gerou uma baixa identificação partidária no país, que permaneceu estável ao longo de todo o período democrático (Rennó, 2007). Estudos realizados no período de 1989 a 2002 apontam que a média de preferência por algum partido político girou em torno de $46,5 \%$ do eleitorado em todo o período (Carreirão e Kinzo, 2004).

No período entre 2002 e 2010, os índices de identificação partidária se estabilizaram na média de 39\% (Veiga, 2011), o que se coloca como um elemento positivo dada a emergência de escândalos de corrupção ${ }^{3}$. Dentre os partidos de maior identificação partidária, registra-se uma acentuada polarização entre o PT e o PSDB (Zucco Junior, 2014). Os dois partidos disputam as eleições com candidatos próprios desde o restabelecimento de voto direto na disputa majoritária, e se configuram como duas forças contrárias em um terreno de disputa política (Melo, 2014). Os partidos menores, nesse contexto, não receberam o mesmo apoio que essas duas legendas. Os

\footnotetext{
${ }^{3}$ Em 2005, com a emergência de denúncias de corrupção envolvendo grandes partidos nacionais, o índice de identificação partidária caiu para 28\%, o menor percentual em todo o período pós-democratização. Contudo, até o fim da década, os valores voltaram a ser revertidos (Veiga, 2011).
} 
estudos na área de cultura política apontam tal circunstância ao número de partidos que existem no Brasil e a dificuldade dos eleitores em se apropriarem da lógica eleitoral e conhecerem a fundo todos os partidos (Gimenes, 2015), prevalecendo uma alternância entre as duas forças contrárias no Executivo Federal que perdurou por 20 anos.

O Partido Social Democrata governou o país de 01 de janeiro de 1995 a 31 de dezembro de 2002, através da gestão de Fernando Henrique Cardoso. Em janeiro de 2003, pela primeira vez na história do país, um governo popular assume a Chefia do Poder Executivo. Sua vitória decorreu da congruência de uma série de fatores, como a existência de coligações favoráveis (Telles, 2003) e aproximação das classes menos favorecidas (Venturini, 2010). Ao longo do primeiro mantato, o PT foi feliz em conciliar os interesses do capital com seu projeto de governo (ibidem), o que - junto com a avaliação positiva do governo (Rennó, 2007) fortelecida por políticas sociais efetivas (Singer, 2012) e o bom desempenho econômico do país (Couto, Abrucio e Teixeira, 2013) - conduziram Luis Inácio Lula da Silva à reeleição em 2006. Há de se ressaltar que os escandalos de corrupção envolvendo importantes líderes partidários não desgastou significativamente a imagem do PT, o que demonstra a boa recepção do partido em importantes segmentos sociais nacionais (Telles, 2012).

A perspectiva política favorável contribuiu para que o PT fosse o mais citado nas pesquisas de opinião que objetivavam verificar a identificação partidária dos brasileiros nos anos de 2002 e 2006 (Nicolau e Peixoto, 2007). Contudo, se comparadas as duas eleições presidenciais, a literatura registrou uma ligeira queda no favoritismo do partido - visto que taxa de identidade caiu dos 23 para os 18 pontos (Veiga, 2007) já demonstrando o inicio de um desgaste com a relação do eleitorado que não se reverteu em identificação com os demais partidos políticos relevantes naquele contexto (idem).

A observação do comportamento eleitoral nas eleições de 2010 indicou um agravamento da tendência diagnosticada em 2006, visto que mais da metade da população pesquisada declarou não se identificar com qualquer partido político (Paiva 
e Tarouco, 2011). Dentre aqueles que declararam sua preferência, o PT apareceu como o mais bem cotado, seguido pelo PSDB e o PMF, respectivamente (idem).

O quadro eleitoral de 2014 - caracterizado pela polarização PT e PSDB apresentou detalhamentos mais específicos. Além do descréscimo no indíce de identificação partidária positiva com os dois partidos (Paiva, Krause e Lameirão, 2016), também se passou a registrar um significativo sentimento de identificação partidária negativa, dirigido principalmente ao partido de situação que buscava a quarta reeleição sucessiva para a Chefia do Poder Executivo (idem). A partir do resultado das eleições presidenciais - que conduziram a então Presidenta Dilma ao segundo governo - observou-se um acréscimo na identificação com discursos partidários de caráter liberal no âmbito econômico e conservador no domínio da moral até então inéditos no experimentalismo democrático recente (Codato, Bologanesi e Roeder, 2015). Os efeitos de tal discurso ainda carecem de maiores explicações, mas a observação dos eventos que sucederam o resultado eleitoral aponta para uma ampliação na identificação com a direita.

\section{A reorganização da direita e o surgimento dos movimentos estudados}

Talvez uma das maiores novidades no contexto brasileiro atual seja a emergência de uma corrente que proclame sua posição ideológica à direita no espectro político. Esse orgulho direitista parece contrastar com a história de uma sociedade na qual a "direita" em geral assumiu uma conotação pejorativa. A exemplo disso, pesquisas de opinião conduzidas no Congresso Nacional apontam que os parlamentares, no início da década de 1990, preferiam ser classificados como partidos "de centro" em detrimento de seu evidente posicionamento no campo da direita (Mainwaring, Meneguello e Power, 2000).

Essa retração na demarcação do posicionamento ideológico persistiu no início dos anos 2000. No ano de 2003 - dando início a um ciclo que se repetiria em outros países da América Latina e que ficou conhecido como "maré rosa" (Levitsky e Roberts, 2011; Weyland, 2009) - o PT assumiu a chefia do Poder Executivo Nacional. Após mais 
de dez anos de governança petista, o partido começou a apresentar os primeiros sinais de desgaste, visto que ficou gradativamente mais complicado conter os efeitos da crise global sobre a economia local, comprometendo a promessa de desenvolvimentismo firmada nos anos anteriores (Codato, Bolognesi e Roeder, 2015). Em alguma medida, esse efeito foi sentido em toda a América Latina, que passou a vivenciar progressivamente o ressurgimento de uma nova direita que passou a defender uma concepção de mundo amplamente baseada nas críticas às reformas e programas sociais e aos direitos de minorias garantidos pelas esquerdas que governavam a região (Panizza, 2005).

No Brasil, os primeiros indícios de uma nova organização de direita pôde ser sentido a partir de 2007, com a criação de coletivos de contestação das políticas governamentais. A primeira aparição pública de cunho anti-governista se deu no dia 29 de junho de 2007, por ocasião de uma manifestação relembrando as 119 vítimas do maior acidente aéreo da história brasileira (Oliveira, 2007). Entoando gritos de ordem requerendo o fim da corrupção e a saída do então Presidente Lula, foi fundado naquele ato o coletivo CANSEI, autoidentificado como um Movimento Cívico pelo Direito dos Brasileiros (Tatagiba, Trindade e Teixeira, 2015). Foi organizada pelo movimento uma segunda manifestação, no dia 17 de agosto de 2007 na Praça da Sé (São Paulo - SP), na qual foi relembrada a passagem de um mês do acidente da empresa aérea Tam e foi também exigida a condenação de políticos corruptos (Capriglione, et al., 2007).

Os sujeitos tocados com o discurso iniciado nas ruas em 2007 seguiram contestando as políticas governamentais e a promessa de hegemonia petista. Em 1 de agosto de 2010, foi criado o movimento Revoltados OnLine (ROL), caracterizado como um movimento anti petista de atuação majoritariamente virtual (Dias, 2017). Apesar de a organização possuir células em cidades no Brasil e no exterior, ela é altamente hierarquizada (idem) e centralizada nos coordenadores Marcello Reis, Beatriz Kicis, Patrícia Mello, Rodrigo Brasil e Valéria Andrade (Abrantes, 2015; Poletti, 2016; Redação Época, 2016). Autodenominando-se como a primeira organização virtual de combate a corrupção que vai com tudo para cima dos corruptos, o ROL se articulou em torno de 
importantes demandas políticas nacionais desde sua criação, protagonizando importantes espaços nas manifestações que ocorreram no Brasil em 2015 e 2016.

Dois anos mais tarde, Ricardo Salles funda o Movimento Endireita Brasil (MEB), que se auto intitula uma organização de direito privado sem fins lucrativos ou vínculos partidários comprometida com a difusão do ideário conservador e de direita no Brasil (Movimento Endireita Brasil, 2012). O movimento tem por objetivo, dentre outros, a doutrinação, a educação e a formação políticas, a orientação da cidadania, os direitos humanos do cidadão de bem, a manutenção da família constituída por marido e mulher, a promoção do desenvolvimento econômico sustentável e social com ênfase na iniciativa privada, a defesa dos valores éticos e morais e a luta intransigente contra a corrupção (Estatuto Instituto Endireita Brasil, artigo $2^{\circ}$ ). O Estatuto prevê uma estrutura organizacional capilarizada, no qual consta uma sede nacional (situada na cidade de Fortaleza-CE), Diretórios Estaduais e Municipais (Estatuto Instituto Endireita Brasil , artigo $4^{\circ}$ ). Contudo, os estudos sobre o movimento apontam que suas ações e estratégias se concentram na Executiva Nacional (Bueno, 2016). O movimento se articula em torno de demandas de cunho liberal, como a diminuição do Estado brasileiro, redução das cargas tributárias e a expansão de liberdades individuais, como a posse de armas por civis (Lima, Agostine e Viri, 2015).

O Movimento Brasil Livre (MBL) e o Movimento Vem pra Rua (MVR) foram criados em 2014, em decorrência do resultado eleitoral que conduziu Dilma Rousseff à chefia do Poder Executivo, tendo por objetivo principal questionar a lisura do pleito que a elegeu e a inviolabilidade da urna eletrônica.

Valendo do discurso presente nas manifestações de 2013 - principalmente as críticas às políticas sociais, à corrupção e à gestão do governo nacional - o MBL foi criado no final do ano de 2014, por iniciativa de Juliano Torres, Fábio Ostemann, Felipe França e Renan Santos (Gobbi, 2016). O MBL se colocou como um movimento de pessoas livres e iguais (MBL, 2014), caracterizando através de sua descrição a diversidade populacional brasileira (Moura e Yamamioto, 2016).

Por sua vez, o MVR foi criado em setembro de 2014, comprometido com a luta contra a corrupção e pela promoção da ética na política, privilegiando um Estado desinchado, não interventor e redutor dos impostos (Butterfield e Chequer, 2016). 0 
movimento chamou importantes manifestações após o resultado das eleições presidenciais de 2014, aproveitando-se do clima de polarização, notícias desfavoráveis e queda da popularidade e favoritismo de Dilma (idem).

A primeira ação conjunta dos movimentos - a exceção do MEB, que passou a requerer a saída da Presidente Dilma somente em 2015 - datou do dia 01 de novembro, quando foi chamada uma manifestação na Avenida Paulista. Ela contou com a participação de aproximadamente 2.500 pessoas, demandando o impeachment da presidenta eleita e a extinção do PT (Uribe, Lima e Lima, 2014). O ato foi repetido no dia 15 e 29 de novembro (Chapola e Kattah, 2014) e no dia 06 de dezembro de 2014 (Lima e Machado, 2014).

Ao longo do ano de 2015 , os movimentos oposicionistas ganharam maior espaço midiático e ampliaram sua atuação nas mídias sociais. A aceitação de seu discurso foi reforçada pela crise econômica e a consequente decisão do governo de adotar um conjunto de medidas fiscais (tais como o aumento nos impostos e o corte nos gastos com programas sociais) que geraram um forte descontentamento popular (Tatagiba, Trindade e Teixeira, 2015).

Muitos protestos ocorreram em 2015, o que levou a literatura sobre movimentos sociais considerar esse o principal período de manifestações de direita desde a redemocratização (idem). A primeira daquele ano ocorreu no dia 15 de março e levou aproximadamente 1 milhão de pessoas à Avenida Paulista (Folha de São Paulo, 2015), configurando-se na maior manifestação desde as Diretas Já conforme o Datafolha (Braga, 2015). Uma semana depois, foi realizada uma nova pesquisa de opinião, segundo a qual somente $13 \%$ dos brasileiros consideravam o governo federal bom ou ótimo (Ibope, março de 2015).

Um panelaço foi feito na noite do dia 06 de agosto de 2015, por ocasião da exibição de um programa eleitoral do PT em rede Nacional com duração de dez minutos (Whitaker, 2015). Ele serviu como uma espécie de prévia para a terceira grande mobilização de rua que ocorreria dez dias depois, em todas as unidades da federação, e envolveria um público de aproximadamente 879 mil pessoas (Buscato; et al., 2015). 
Na manhã do dia 02 de dezembro de 2015, Dilma Rousseff recebe a notícia que o então presidente da Câmara de Deputados, Eduardo Cunha, recebeu a denúncia para dar início ao seu impeachment (Gois e Fernandes, 2015). Nove meses depois, no dia 31 de agosto de 2016, se processa a condenação e o afastamento definitivo da líder petista. Ao longo do processamento da denúncia, foram realizadas seis grandes manifestações nas capitais brasileiras, além de serem organizados acampamentos e agitações virtuais motivando a população a se colocar favorável à cassação da Presidenta Dilma. Nesse período, em especial, os movimentos influíram de forma consistente nos rumos políticos nacionais e articularam segmentos populacionais dispersos em torno de demandas em comum relacionadas a defesa de um projeto democrático e de desenvolvimento nacional.

\section{Construção teórico-metodológica}

As grandes manifestações organizadas enquanto tramitava o processo de impeachment da então Presidenta Dilma tiveram, em comum, o clamor pelo afastamento definitivo da candidata petista, a prisão do Ex-Presidente Lula e a garantia do prosseguimento das investigações vinculadas à Operação Lava-Jato (Dias, 2017). Diferentes movimentos, de histórias e influências distintas se articularam para disputar a opinião pública em torno do apoio a cassação da Presidenta da República, promovendo uma ampla campanha virtual e nas ruas. Constituindo como inimigos a militância de esquerda e petista que denunciava a utilização de meios ilegítimos para afastar a então Presidente, os movimentos promoveram agitações e fomentaram um sentimento de ojeriza e escárnio em relação a todos aqueles que não compactuavam com sua perspectiva de mundo.

Em contextos discursivos predominados pela disputa em torno de duas ideias incompatíveis - cujo objetivo de uma é destruir a outra - ganha especial relevância explicativa as ferramentas desenvolvidas por Laclau e Mouffe (Wenman, 2013). Para os dois autores, de grosso modo, o vencedor da disputa é aquele que conseguiu dominar o processo de significação discursiva, constituindo uma hegemonia. Tomando-se o exemplo dos movimentos estudados, tem-se que a articulação de 
sentidos por eles promovida objetivava dominar a significação em torno do impeachment, convencendo um considerável número de pessoas acerca da existência de prática de crime de responsabilidade pela então Presidente Dilma e pela necessidade de seu afastamento definitivo.

Por pressupor a existência de conflitos entre dois campos discursivos distintos aqui compreendidos como os pró impeachment e os contrários ao golpe - a teoria do discurso apresenta importantes ferramentas teóricas que auxiliam na compreensão de fenômenos complexos, destacando-se as noções de discurso, antagonismo, relações de diferença e equivalência e hegemonia.

A primeira definição a ser esclarecida é a de discurso. Afastando-se das correntes linguísticas tradicionais, os autores defendem que "por discurso não se designa somente a palavra ou a escrita, mas todo o tipo de ligação entre as palavras e ações, formando assim totalidades discursivas" (Laclau, 2000, p. 10 apud Mendonça, 2003). Disso se depreende que o discurso não é o enunciado proferido pelos movimentos, mas sim - no âmbito da teoria - os movimentos per si.

A fixação de sentidos parciais se dá por meio de uma prática articulatória. A articulação, segundo os autores, se estabelece entre elementos que, até então, estavam dispersos um em relação ao outro, de forma aleatória, no campo da discursividade. Ela agrega esses elementos - antes dispersos - e os transforma em momentos. Essa transformação resulta na "modificação de identidades, ou melhor, em uma alteração semântica de seus conteúdos particulares anteriores ao seu ingresso na prática articulatória" (Mendonça, 2003, p. 141). O discurso, por sua vez, "é a totalidade estruturada resultante desta prática articulatória." (Laclau e Mouffe, 2015, p. 178).

Disso decorre uma importante consequência: é no interior do discurso que se dá a produção de sentido, que jamais será completa pela impossibilidade de se atingir o sentido último. Assim sendo, a estrutura discursiva somente fixa sentidos parciais, viabilizando a flutuação das diferenças. Laclau e Mouffe esclarecem que "a transformação de elementos em momentos nunca é completa" (Laclau e Mouffe, 2015, p. 194). Isso quer dizer que as identidades se constituem através de uma prática articulatória que, em um dado momento, as uniu em torno de um ponto nodal que 
expressa um sentido comum entre elas. Contudo, suas diferenças não são apagadas, pela própria presença de elementos.

Transpondo a explicação teórica dos autores ao campo a ser estudado, tem-se que cada um dos movimentos se constitui enquanto discursos autônomos. Contudo, quando esses passam a significar de forma semelhante certos temas, eles se aproximam. Essa aproximação, em determinados momentos políticos específicos, é tão aguda que eles se confundem como se fossem um único discurso. Isso é explicado pela noção de antagonismo.

Segundo Laclau e Mouffe, antagonismo é "o limite de toda a objetividade" (Laclau e Mouffe, 2015, p. 198). Pode-se dizer de outra forma que a formação discursiva tem, em dado momento, bloqueada a produção de sentidos pela existência de um discurso que o antepõe. Segundo os autores, "a presença do outro me impede de ser totalmente eu mesmo. A relação não surge de identidades plenas, mas da impossibilidade da constituição das mesmas" (Laclau e Mouffe, 2015, p. 125). Isso quer dizer que a produção de sentidos pelo interior discursivo está limitada pelo exterior antagônico: um discurso surge com a pretensão de preencher todos os sentidos que permitam sua completa universalização. Contudo, o antagonismo - assim como a contingência e a precariedade - inviabilizam a concretização de sua pretensão.

O antagonismo é pré-condição para que se operacionalize entre diferentes discursos relações de equivalência. Elas se dão entre diferentes que, em determinados momentos, compartilham sentidos afins. No caso dos movimentos estudados, tem-se que esses se aproximaram em decorrência de um inimigo comum (ou, utilizando-se da nomenclatura da teoria do discurso, um discurso antagônico) expresso pelo discurso de esquerda. Tomando-se, por exemplo, os movimentos estudados, tem-se que eles atenuam suas diferenças em decorrência da bipolarização política vivenciada pelo país ao longo do processo de cassação da então Presidenta Dilma Rousseff, unificando esforços para atingir um objetivo comum: hegemonizar o discurso em torno do impeachment de tal forma que ficasse evidente a todos a imperiosidade de seu provimento.

Nesse sentido, se introduz a última categoria desenvolvida e que serve como substrato teórico de análise no presente artigo: a noção de hegemonia. O campo 
hegemônico se constitui, necessariamente, quando há duas forças antagônicas e as fronteiras que as separam são instáveis. Explicam os autores que o campo discursivo deve estar preenchido por elementos flutuantes, que podem ser articulados em relações equivalenciais por campos opostos (Laclau e Mouffe, 2015, p. 215). Hegemonizar um conteúdo equivale, nesse sentido, em fixar sua significação em torno de um ponto nodal (Laclau, 2003, p. 45).

O desenvolvimento das categorias anteriores permite inferir que as identidades, no âmbito da teoria do discurso, se constituem de forma relacional: há uma pretensão de universalização dos discursos particulares, nunca concretizada pela presença do antagonismo e pela contingência e precariedade que caracteriza toda a prática discursiva. Nesse contexto, a hegemonia se estabelece quando uma determinada identidade - a partir do estabelecimento de relações equivalenciais passa a representar múltiplas identidades. Conforme Laclau: "entendo por 'hegemonia' uma relação em que um conteúdo particular assume, num certo contexto, a função de encarnar uma plenitude ausente" (Laclau, 2001, p. 122).

Eis que o processo de constituição de uma ordem hegemônica parte sempre de um discurso particular que consegue, por meio de uma relação de equivalência, representar discursos ou identidades até então dispersas. Esta organização ocorre a partir desse discurso centralizador, de um ponto nodal que consegue fixar sua significação e, a partir dela, articular elementos que previamente não estavam articulados entre si.

O objetivo da presente pesquisa é compreender como os movimentos significam e buscam a hegemonia do discurso sobre os sentidos articulados em torno do significante partidos políticos. Tem-se certo que os movimentos guardam grandes críticas ao PT, mas em um contexto de graves denúncias de corrupção, sua descrença também abarca outros partidos ou até mesmo a totalidade da classe política? Para responder a tal questionamento, foram coletadas todas as postagens dos movimentos na rede social Facebook realizadas enquanto tramitou o processo de impeachment. A rede social foi escolhida porque ela se constitui em um importante meio de comunicação e agitação entre as lideranças dos movimentos e usuários simpáticos a 
causa, sendo a principal responsável pelo sucesso nas manifestações. O período foi selecionado porque se considera que, com o recebimento da denúncia do impeachment e com as grandes manifestações que a seguiram, houve uma significativa influência dos movimentos na vida política nacional. Ao total, foram analisadas 5.266 postagens, distribuídas ao longo dos meses da seguinte maneira (Tabela 1):

Tabela 1 - Quantidade de postagens coletadas nas páginas oficiais dos movimentos no período analisado

\begin{tabular}{llllllllll}
\hline & Dez & Jan & Fev & Mar & Abril & Mai & Jun & Jul & Ago \\
MBL & 224 & 193 & 148 & 219 & 243 & 187 & 231 & 239 & 247 \\
VRB & 173 & 157 & 132 & 136 & 185 & 143 & 155 & 207 & 216 \\
R.OI & 82 & 63 & 46 & 54 & 86 & 39 & 53 & 72 & 97 \\
MEB & 143 & 137 & 97 & 114 & 156 & 119 & 126 & 184 & 163 \\
\hline
\end{tabular}

Fonte: elaborado pela autora.

A fim de responder ao problema de pesquisa colocado, selecionaram-se somente aquelas postagens que tinham como conteúdo principal ou secundário a democracia brasileira, os partidos políticos brasileiros ou as lideranças políticas nacionais. É importante destacar que, para que fossem analisadas, as postagens deveriam trazer expressamente no texto o nome de algum partido político, o nome de alguma liderança nacional, ou as palavras democracia, partido(s) político(s) ou político (s, a, as). Nesse sentido, verificou-se que tais palavras apareceram em um total de 1.858 postagens, distribuídas da seguinte forma:

Tabela 2 - Postagens dos movimentos sobre partidos políticos no período analisado

\begin{tabular}{llllllllll}
\hline & Dez & Jan & Fev & Mar & Abril & Mai & Jun & Jul & Ago \\
MBL & 92 & 83 & 54 & 45 & 127 & 43 & 82 & 78 & 89 \\
VRB & 53 & 64 & 43 & 34 & 87 & 32 & 24 & 83 & 54 \\
R.OL & 34 & 21 & 17 & 12 & 31 & 9 & 8 & 13 & 24 \\
MEB & 87 & 78 & 31 & 36 & 72 & 34 & 32 & 65 & 87 \\
\end{tabular}


Fonte: elaborado pela autora.

Os dados coletados foram sistematizados em uma tabela do Excel e importados para análise no software NVivo. No interior do programa, cada uma das postagens foi analisada e classificada de acordo com os sentidos presentes. A utilização do software, nesse momento, foi crucial porque ele apresenta uma ferramenta - denominada nós ou nodes - que propicia a criação livre de categorias que tenham por condão aproximar postagens com temáticas afins. A metodologia se construiu conforme a indicação dos próprios discursos, visto que análise individual de cada postagem indicou os sentidos discursivos presentes e eles foram - de acordo com suas particularidades classificados em distintos nós. Ao fim do trabalho, verificou-se a existência de três nós: as críticas ao PT, o mapeamento do comportamento eleitoral dos partidos políticos durante o impeachment e renovação política.

Por fim, aproximando o material coletado da teoria, buscou-se identificar se os sentidos constituíam os quatro discursos, colocando-os em relações de equivalência ou de diferença. Em última instância, buscava-se verificar se os movimentos buscavam atingir a hegemonia no processo de significação em torno da questão partidária nacional e quais as estratégias empregadas para tanto.

\section{A articulação dos movimentos em torno do discurso partidário}

Baseada nos dados coletados na presente pesquisa, verifica-se que os sentidos discursivos articulados em torno do significante partidos políticos e afins recebem significativa atenção por parte dos movimentos estudados, correspondendo a 51,13\% da cobertura total das postagens colhidas no período. Proporcionalmente, o discurso está presente de igual forma entre os grupos, o que permite inferir que se trata de uma pauta comum a todos eles. Quantitativamente, o MBL é o que tratou mais vezes do assunto em suas postagens, totalizando 693 recorrências.

A análise mais detalhada de cada umas das postagens demonstrou que 0 processo de significação é diverso e se estabelece de acordo com o contexto discursivo 
que dá suas condições de emergência. Conferindo aos quatro discursos um caráter espontâneo e atenta às peculiaridades que caracterizam o período analisado, a metodologia de pesquisa foi construída buscando verificar a existência ou não de aproximações ou distanciamentos entre eles.

Conforme ressaltado no tópico anterior, verificou-se que em torno do significante se articularam três significados distintos: o ódio ao PT, um mapeamento do comportamento dos partidos políticos durante o processo de impeachment e a necessidade de renovação política. O primeiro significado é o de maior recorrência, se fazendo presente em $83,4 \%$ da cobertura analisada, seguido pelos dois outros nós, respectivamente, com uma cobertura de $9,1 \%$ e 7,5\%. Em números absolutos, a classificação das postagens entre os três grandes temas seu deu como demonstrado (Tabela 3).

Tabela 3 - Distribuição das postagens entre os três nós analisados

\begin{tabular}{lllll}
\hline & ROL & MEB & MBL & MVR \\
Críticas ao PT & 146 & 419 & 594 & 389 \\
$\begin{array}{l}\text { Mapeamento do comportamento dos partidos } \\
\text { políticos durante o impeachment }\end{array}$ & 14 & 47 & 76 & 31 \\
Renovação política & 9 & 53 & 23 & 54 \\
\hline
\end{tabular}

Fonte: elaborado pela autora.

A análise quantitativa da classificação proposta já aponta que há uma aproximação entre os quatro movimentos em se tratando de uma leitura da organização partidária nacional, indicando a existência de relações de equivalências. Contudo, conclusões definitivas sobre aproximações e diferenciações entre os movimentos exige uma análise aprofundada dos significados e de seus contextos discursivos, que será feita nos próximos parágrafos atentando - do menor para o maior - o índice de cobertura de cada um dos nós.

A análise do primeiro e mais recorrente sentido - críticas ao PT - assumiu três caráteres distintos, presentes nos quatro discursos: o primeiro o vinculava com um 
modelo de corrupção sistêmica que deveria ser combatido, o segundo questionava a capacidade de gestão e liderança dos candidatos petistas eleitos, principalmente Dilma e Lula, e o terceiro tinha por pretensão convencer os apoiadores e simpatizantes a reduzirem a influência do partido da política.

Cunhando termos como "CorruPTos" e promovendo uma ampla divulgação das delações ocorridas na Operação Lava-Jato que envolvia lideranças petistas, os movimentos buscaram construir uma retórica no sentido de construir um imaginário popular que vinculasse a saída do PT da política a uma queda brusca da corrupção. Em entrevista concedida à TV Cultura $(11 / 12 / 15)^{4}$, Kim Kataguiri - influente líder do MBL esclareceu que eles se colocavam contra o PT porque ele havia disseminado a corrupção como forma de governo, através da compra de cargos, de votos e desvios de dinheiro público. Por conta da banalização da prática corruptiva, sua influência era mais nefasta do que as exercidas pelos demais partidos e políticos e, por essa razão, ele deveria ser banido da vida pública. Nesse mesmo sentido, o ROL se posicionou

\begin{abstract}
A quantia certa de dinheiro desviado por este governo corruPTo é estimada, em pouco mais de 724 BILHÕES, é isso mesmo o q vc está lendo, são BILHÕES e BILHÕES do nosso suado dinheiro, desviados para os bolsos de uma verdadeira QUADRILHA q se instalou em Brasília, se bem q eles foram criados nos porões do palácio e sabem como ninguém ROUBAR, pq administrar não é com esta turma de incomPTentes... Graças ao nosso respeitável público q elegeu e colocou democraticamente uma assaltante de bancos, sequestradora guerrilheira e terrorista no poder do Braziú, chega a ser INACREDITÁVEL falar isso, mas é a mais pura realidade de nosso país q dorme em berço esplêndido, sendo complacente com os piores crimes cometidos contra o erário e contra quem vai de contra elles, como no caso do Prof. Toninho do PT e do Celso Daniel...(sic) (ROL, 04 de março de 2016) ${ }^{5}$.
\end{abstract}

Outro dado importante sobre a visão que os movimentos têm do partido está explicita no trecho "se bem q elles foram criados nos porões do palácio e sabem como ninguém ROUBAR, pq administrar não é com esta turma de incomPTentes..." (sic). Comparando as lideranças partidárias do PT a ratos, eles constroem a ideia de que se tratam de pessoas que ocuparam a política de forma indesejável e que detém parcas

\footnotetext{
${ }^{4}$ MOVIMENTO BRASIL LIVRE. Disponível em: < https://www.youtube.com/watch?v=skllO60DzgE> Acesso em: out. de 2017.

${ }^{5}$ REVOLTADOS ONLINE. Disponível em: <https://www.facebook.com/ronline/photos/a.204296283027856.1073741829.204223673035117/332 653796858770/?type=3> Acesso em: ago. de 2016.
} 
qualidades morais ou intelectuais para exercer a governança do país, uma vez que eles usufruem do dinheiro público para seus interesses particulares e são incapazes de trazer soluções para os problemas enfrentados pelo Brasil.

Vinculando a imagem dos líderes petistas a sujeitos habituados a gastarem mais do que o possível em políticas sociais de cunho populistas, descomprometidos com o desenvolvimento econômico e com os interesses do médio empresariado, os gestores foram significados como figuras despreparadas e os principais culpados pela crise econômica que o Brasil vinha enfrentando. Nesse sentido, os movimentos promoveram agitações dizendo que "O desemprego no Brasil é recorde. Se você não aguenta a incompetência da Dilma, vem pra rua!” (MVR, 13 de dez. 2015) ${ }^{6}$, “10\% de inflação. A cada mês que passa, a incompetência da Dilma come mais o seu salário. Se você não aguenta mais, vem pra rua!" (MEB, 12 de fevereiro de 2016). O ROL denunciou que:

\begin{abstract}
Segundo informe fidedigno, a cúpula do PT se reuniu e um dos assuntos da pauta foi a aprovação do poupança fraterna, projeto antigo do PT de confiscar o dinheiro de quem ganha mais de 9 mil reais por mês...com este confisco o PT vai aumentar o Bolsa Família...ou seja, tira de quem trabalha para dar para quem não trabalha...Essa será mais uma tentativa do PT de se perpetuar no poder... (ROL, maio de 2016) ${ }^{7}$.
\end{abstract}

Os exemplos trazidos no texto demonstram que a insurgência dos movimentos não reside sobre as práticas corruptivas exercidas pela classe política, e sim contra o PT e sua política de implementação de políticas sociais para reduzir a desigualdade de renda e promover a inclusão das classes mais baixas pelo consumo. Eles são acusados de onerar em demasia a classe produtiva do país em prol do contingente de brasileiros não incluídos no mercado de trabalho, fazendo uso de medidas populistas para se perpetuarem no poder.

Por isso os movimentos frisavam a união de todos os brasileiros descontentes com a desmoralização da política para se manifestarem e pressionarem os parlamentares a darem fim ao mandato de Dilma Rousseff e todas as práticas ilícitas

\footnotetext{
${ }^{6}$ MOVIMENTO VEM PRA RUA. Disponível em:

<https://www.facebook.com/vemprarua.net/photos/a.344411022406919.1073741828.3444084924071

72/929600078797986555679867> Acesso: out. de 2016.

${ }^{7}$ REVOLTADOS ONLINE. Disponível em:

<https://www.facebook.com/ronline/photos/a.204296283027856.1073741829.204223673035117/336

43434296858770/?type=3> Acesso em: ago. de 2016.
} 
que a ela estavam vinculadas. O PT se constituiu, no período do impeachment, enquanto discurso antagônico ao discurso dos movimentos, que se articularam em relações de equivalência com um objetivo específico: reduzir a influência política do partido, buscando diminuir seu índice de identificação partidária.

Relacionado ao primeiro sentido, contudo sem se confundir com ele, constam os sentidos discursivos classificados no segundo nó, que diziam respeito ao convencimento das demais lideranças políticas em torno da causa do impeachment. De se destacar, nesse sentido, que os quatro movimentos dividiram a classe política entre os apoiadores de Dilma e os partidos comprometidos com a causa republicana, que abertamente haviam se declarado apoiadores da cassação definitiva do mandato da então Presidenta. Tal perspectiva fica clara no trecho abaixo:

\begin{abstract}
Nós temos que ver que a classe política brasileira não é de todo mal. Nós temos políticos de valor - como é o caso de Marcelo Van Hatten, do Senador Caiado e até mesmo do Maia - que têm ideais republicanas e querem ver o Brasil ir pra frente. É lógico que tem esses partidos menores, de esquerda, que merecem todo o nosso desprezo. Eles estão ali, agarrados no PT, pra ver se conseguem um carguinho aqui ou ali. E eles só fazem isso porque sabem que com esses outros partidos eles não vão conseguir nada (MBL, maio de 2016) $)^{8}$.
\end{abstract}

O trecho vem a reproduzir uma ideia muito recorrente nas demais postagens classificadas, consolidando o entendimento de que nem toda a classe política deve ser repudiada. Eles defendem a percepção de que existem políticos bons, efetivamente comprometidos com a causa republicana (expressa, na perspectiva dos movimentos, pelo apoio ao impeachment) e que os maus políticos deveriam sofrer as reprimendas e serem desalojados do protagonismo político.

Para denunciar tais políticos, bem como constrangê-los a mudarem seu posicionamento, os movimentos empregaram táticas de denúncia e controle parlamentar. Eles operacionalizaram tal objetivo através da divulgação dos dados pessoais e contato oficial dos parlamentares que se declaravam favoráveis ou indecisos em relação ao impeachment, para que seus seguidores os pressionassem a mudar de opinião. O MBL divulgou tal tática com o nome de "Operação Minerva". Já o MVR, com os mesmos objetivos, desenvolveu um aplicativo denominado "Mapa do

\footnotetext{
${ }^{8}$ MOVIMENTO BRASIL LIVRE. Disponível em: < http://mbl.org.br/e-confirmado-dilma-cometeu-umautentico-atentado/> Acesso: out. de 2016.
} 
Impeachment, que continha informações com o nome, telefone, endereço e o posicionamento sobre o impeachment de cada um dos 513 deputados. Outra tática de constranger os favoráveis a manutenção de Dilma Rousseff na Chefia do Poder Executivo era exibi-los em grandes banners nos locais de maior circulação das capitais estaduais, denominados "Muros da Vergonha". O objetivo de tais iniciativas era muito claro

Nós queremos tirar essas pessoas da política. Todos devem saber quem são essas pessoas, para não votar nelas e nem no partido delas nas próximas eleições federais e municipais. Essas pessoas têm de sair da política, porque o político tem de ouvir o povo. E o que o povo quer hoje é a saída de Dilma Rousseff. Quer o fim dessa vergonha nacional, dessa corrupção sem limites. O povo quer algo novo, políticos que eles podem confiar (MEB, maio de $2016)^{9}$

Para além do impeachment, os movimentos buscavam retirar da política aqueles comprometidos com a ideologia e projetos petistas, compreendidos como nefastos ao desenvolvimento nacional. Nesse contexto, compreende-se os sentidos articulados em torno do terceiro nó, que diz respeito a uma necessária renovação da política. Explica o MVR que:

Nós precisamos renovar a política e os políticos. Esse movimento que nós criamos, nunca visto na história do Brasil, tem também esse propósito. Quando a gente tira da política gente incompetente, que governa pensando em seus próprios interesses, temos que colocar outra pessoa lá. Pessoas que buscam uma forma melhor de fazer política, conciliando a necessidade de crescer com a responsividade econômica. Nós temos de buscar, em nós mesmos, quem são essas pessoas. E temos de motivá-las no campo da política, apoiar sua candidatura. É só assim que vamos mudar o Brasil (MVR, junho de 2016) ${ }^{10}$

O trecho destacado está de acordo com o entendimento expresso nos quatro movimentos, que defende que o espaço deixado pelos políticos simpáticos à causa do PT deve ser ocupado por pessoas de boa índole moral e comprometidas o liberalismo. Diz o ROL que "não quero ver mais gente defendendo homossexualismo no congresso. Quero ver gente defendendo educação, saúde de qualidade. Gente de bem, gente que quer melhorar o Brasil” (ROL, julho de 2016) ${ }^{11}$. Nesse mesmo sentido, já antecipando a

\footnotetext{
${ }^{9}$ MOVIMENTO ENDIREITA BRASIL. Disponível em: <https://www.facebook.com/endireitabrasil/posts/10153458738152344. > Acesso: nov. de 2016

${ }^{10}$ MOVIMENTO VEM PRA RUA. Disponível em: <https://www.Facebook.com/vemprarua.net/photos/a.344411022406919.1073741828.3444084924071 72/9296000705546008> Acesso: set. de 2016.

${ }^{11}$ REVOLTADOS ONLINE. Disponível em:
} 
bem-sucedida campanha a vereador do líder Fernando Holiday, diz o MBL que "precisamos de pessoas que unam a sociedade, não que dividem a sociedade entre pretos e brancos, pobres e ricos, homossexuais e heterossexuais" (MBL, agosto de 2016) ${ }^{12}$. Em larga síntese, o que buscam os movimentos é um afastamento da política daqueles não simpáticos à sua causa e uma substituição eleitoral por políticos ideologicamente mais próximos.

A análise dos três sentidos aponta que, no período explorado, a preocupação dos movimentos está direcionada em reduzir a influência política de partidos identificados com a ideologia de esquerda - destacando-se, nesse sentido, a atuação do PT - e na consolidação de um discurso de direita mediante a valorização e ampliação quantitativa dos parlamentares comprometidos com tal perspectiva ideológica. De se destacar, aqui, que os quatro discursos partem da premissa de que a democracia se consolida a partir da representação institucional, visto que em qualquer momento se registrou preocupação na ampliação dos meios de controle popular ou de expansão das formas de participação política direta. Pode-se dizer que, em torno dos três sentidos, os quatro movimentos se colocaram em relações de equivalência, buscando hegemonizar o campo político em torno de um discurso anti-petista e antiesquerdista que visa firmar uma perspectiva política de direita.

\section{Considerações finais}

A mudança no perfil dos partidos políticos, que deslocaram suas práticas da intermediação entre os interesses do Estado e da sociedade para focarem-se na composição de governo, vinculado a déficit de cidadania no Brasil propiciou um cenário de baixo interesse na vida pública e de pouca identificação com os partidos políticos. Por outro lado, o sucesso eleitoral do PT - que venceu por quatro vezes consecutivas 
as eleições presidenciais e cresceu no índice de identificação partidária - estimulou a criação de grupos de contestação simpáticos ao ideário liberal-conservador, que tomou as ruas do país e exerceu significativa influência na crise política vivida pelo país em 2016 que cominou com a cassação da Presidenta Dilma Rousseff.

O objetivo do presente trabalho é analisar o discurso desses movimentos sob a ótica da teoria do discurso de Laclau e Mouffe, visando definir se o discurso antipartidário dos movimentos era dirigido exclusivamente ao PT ou se ele atingia a classe política como um todo. A análise das postagens na rede social Facebook aprontou que em torno de $83,4 \%$ das críticas eram dirigidas exclusivamente ao PT, construindo a imagem de que o partido era adepto a práticas corruptivas, era incompetente ao administrar e deveria ser banido das atividades públicas. Ainda se relacionando ao primeiro sentido, verificou-se que $9,1 \%$ dos sentidos articulados tinham por objetivo articular a classe política em torno da procedência do impeachment, demonstrando o desejo imediato de reduzir - senão abolir - a influência política petista. O terceiro sentido - de menor recorrência e presente em 7,5\% das postagens, demonstrou que os movimentos buscam ocupar os vácuos deixados na política com novos atores, comprometidos com a ideologia conservadora no âmbito moral e liberal no domínio econômico.

Nesse sentido, conclui-se que o discurso dos movimentos apresenta um caráter contraditório no sentido de que - ao mesmo tempo em que é colocado como objetivo politizar a política - eles buscam excluir da esfera pública aqueles que não concordam com eles. Percentualmente, os sujeitos que deveriam perder a representatividade política correspondem a maior parte dos eleitores com identificação partidária, o que fragiliza muito a democracia. O discurso também apresenta um caráter ambivalente, na medida em que - sob uma promessa de renovação política - eles acabam por consolidar lugares comuns e favorecem os velhos interesses da elite nacional, enfraquecendo um ideal de expansão democrática. Há de se ter presente, não obstante, que os resultados aqui aventados sugerem a ampliação da agenda de pesquisa sobre o discurso antipartidário no Brasil, considerando que o período estudado foi de ampla polarização política. 


\section{Referências bibliográficas}

Abrantes, T. 2017. Quem são e o que defendem os líderes dos protestos do dia 15. Disponível em: <http://exame.abril.com.br/brasil/quem-sao-e-o-que-pensam-os-lideres-dos-protestos-dodia-15/>. Acesso em: nov. 2017.

Alcántara Saez, Manuel \& Freidenberg, Flávia. 2002. "Partidos Políticos na América Latina". Revista Opinião Pública, n8, v.2, pp. 137-157.

Baquero, Marcelo. 2000. A vulnerabilidade dos partidos políticos e a crise da democracia na América Latina. Porto Alegre: Universidade Federal do Rio Grande do Sul.

Baquero, Marcelo \& Linhares, Bianca. 2010. "Democracia, desigualdades, capital social e cultura política no Brasil". Seminário Internacional Movimentos Sociais, Participação $e$ Democracia. Anais. Florianópolis: Universidade Federal de Santa Catarina, pp. 787-809.

Braga, Fábio. 2015. "Paulista reúne maior ato político desde as Diretas Já, diz Datafolha". Folha de São Paulo Online. Disponível em: http://www1.folha.uol.com.br/poder/2015/03/1603271paulista-reune-maior-ato-politico-desde-as-diretas-ja-diz-datafolha.shtml. Publicado em: 15 mar. 2015. Acesso em: nov. 2017.

Braga, Maria do Socorro. 2006. O processo partidário-eleitoral brasileiro: padrões de competição política (1982-2002). São Paulo: Humanitas.

Buscato, Marcela el al. 2017. "16 de agosto: as manifestações pelo Brasil". Revista Época. Disponível em: http://epoca.globo.com/tempo/noticia/2015/08/16-de-agosto-manifestacoespelo-brasil.html. Publicado em: 16 ago. 2015. Acesso em: nov. 2017.

Butterfield, Colin \& Chequer, Rogério. 2016. Vem Pra Rua. São Paulo: Matrix.

Capriglione, Luciana et al. 2017. "Na Sé, 'Cansei' desemboca em 'fora, Lula'”. Folha de São Paulo Online. Disponível em: <www1.folha.uol.com.br/fsp/brasil/fc1808200706.htm>. Publicado em: 18 ago. 2007. Acesso em: 01 out. 2017.

Carneiro, Gabriela \& Moisés, José. 2015. "Sobre o enraizamento dos partidos políticos na sociedade brasileira". Revista Interesse Nacional, a.7, n²8, p. 20-37, jan-mar.

Carreirão, Yan. 2014. "O sistema partidário brasileiro: um debate sobre a literatura recente". Revista Brasileira de Ciência Política. n¹4, p. 255-295, mai-ago.

Carreirão, Yan \& Kinzo, Maria. 2004. "Partidos políticos, preferência partidária e decisão eleitoral no Brasil (1989-2002)". Revista Dados. v.47, n¹, p. 131-168.

Chapola, Ricardo \& Kattah, Eleonora. 2017. “Protesto contra Dilma reúne 500 pessoas na Paulista". O Estadão Online. Disponível em:

http://politica.estadao.com.br/noticias/geral,protesto-contra-dilma-reune-500-pessoas-napaulista,1599897> Publicado em: 29 de Nov. 2014 Acesso em: nov. 2017. 
Codato, Adriano; Bolognesi, Bruno; Roeder, Karolina. 2015. "A nova direita brasileira: uma análise da dinâmica partidária e eleitoral do campo conservador". In: Cruz, Sebastião; Kaysel, André; CODAS, Gustavo (Orgs.). Direita Volver! O retorno da direita e o ciclo político brasileiro. São Paulo: Editora Perseu Abramo, pp. 115-144.

Couto, Claudio; Abrucio, Fernando; Teixeira, Marco. 2013. "As eleições municipais de 2012 e seus efeitos nacionais". Cadernos Adenauer, v. 14, no2, pp. 193-207.

Dalton, Russel. 2013. The apartisan American: Dealignment and Changing Electoral Politics. Washington D.C: Sage Publications.

Dias, Tayrine. 2017. É uma batalha de narrativas: os enquadramentos da ação coletiva em torno do impeachment de Dilma Rousseff no Facebook. Dissertação apresentada à Universidade Nacional de Brasília para a obtenção do grau de Mestre.

Folha de São Paulo. 2015. "Protestos contra o governo reúnem quase um milhão pelo país". Folha de São Paulo Online. Disponível em: http://www1.folha.uol.com.br/poder/2015/03/1603286-protestos-contra-o-governo-reunequase-1-milhao-pelo-pais.shtml. Publicado em: 15 Mar. 2015. Acesso em: nov. de 2016.

Gimenes, Éder. 2015. A Relação dos eleitores com partidos políticos nas novas democracias: partidarismo na América Latina. Tese apresentada à Universidade Federal de Santa Catarina para a obtenção do grau de Doutor.

Gimenes, Éder. 2014. "A situação dos Partidos Políticos na América Latina no Início do Século XXI: Crise ou Estabilidade?" Revista Andina de Estudios Políticos. v. IV, n 1, pp. 4-19.

Gimenes, Éder \& Borba, Julian. 2016. "Mobilização Cognitiva e Perfis Eleitorais na América Latina". Anais do X Encontro Brasileiro de Ciência Politica: Ciência Política e a Política Memória e Futuro. Belo Horizonte.

Gobbi, Danniel. 2016. Identidade em ambiente virtual : uma análise da Rede Estudantes Pela Liberdade. Dissertação apresentada à Universidade de Brasília para a obtenção do grau de Mestre.

Gois, Chico; Fernandes, Letícia. 2015. "Cunha aceita pedido de Impeachment contra Dilma". $O$ Globo. Disponível em: <https://oglobo.globo.com/brasil/cunha-aceita-pedido-deimpeachment-contra-dilma-18202665> Publicado em: 02 dez. 2015. Acesso em: nov. 2017.

Ibope. 2015. "Pesquisa CNI/IBOPE. Avaliação do governo: março de 2015". CNI [online]. Disponível em: http://www.ibope.com.br/pt-br/noticias/Documents/Pesquisa\%20CNIIBOPE\%20Aval\%20do\%20governo\%20-\%20mar2015.pdf

Inglehart, Ronald. 1977. The Silent Revolution Changing Values and Political Styles Among Western Publics. Princeton: Princeton University Press.

Laclau, Ernesto. 2003. Nuevas Reflexiones sobre la Revolución de Nuestro Tiempo. Buenos Aires: Nueva Verson.

Laclau, Ernesto; Mouffe, Chantal. 2015. Hegemonia e Estratégia Socialista: por uma política democrática radical. São Paulo: Intermeios. 
Levitsky, Steve; Roberts, Kay. 2011. The Resurgence of the Latin American Left. Baltimore: Johns Hopkings.

Lima, Dílson; Machado, Luís. 2014. "Manifestantes em SP protestam contra Dilma e escândalo na Petrobrás". Folha de São Paulo Online. Disponível em: www1.folha.uol.com.br/poder/2014/12/1558809-manifestantes-em-sp-protestam-contradilma-e-escandalo-na-petrobras-shtml> Publicado em: 06 dez. 2014 Acesso em: nov. 2017.

Lima, Flávia; Agostine, Cristiane; Viri, Natalia. 2015. "Com pauta liberal, Endireita Brasil vê PT como pior partido". Valor. Disponível em: <http://www.valor.com.br/politica/4181576/compauta-liberal-endireita-brasil-ve-pt-como-pior-partido>. Acesso em: nov. 2017.

Mainwaring, Scott; Meneguello, Rachel; Power, Timothy. 2000. Partidos conservadores no Brasil contemporâneo. São Paulo: Paz e Terra.

Mair, Peter. 2000. "Há um futuro para os partidos?" Revista Política Democrática, v.1, pp. 147160.

Mair, Peter. 2003. “Os partidos políticos e a democracia”. Revista Análise Social, v. 38, no 167, pp. 277-293.

Mair, Peter \& Van Biezen, Ingrid. 2001. "Party Membership in Twenty European Democracies, 1980-2000". Party Politics, v.7, n¹, pp. 5-21.

Melo, Cristiano. 2014. Relatório Final de Conferência na Sessão Especial "Democracia e Novos Partidos: reacomodação das elites e sistema partidário no Brasil". In: Encontro da Associação Brasileira de Ciência Política, Brasília.

Mendonça, Daniel. 2003. "A noção de antagonismo na Ciência Política contemporânea: uma análise a partir da teoria do discurso". Revista de Sociologia e Política, v. 1, n²0, pp. 135-145.

Miguel, Luis Felipe \& Machado, Carlos. 2010. "De partido de esquerda a partido do governo: O PT e suas coligações para prefeito (2000 a 2008)". In: Krause, Silvana; Dantas, Humberto; Miguel, Luis Felipe. Coligações partidárias na nova democracia brasileira: perfis e tendências. Rio de Janeiro/São Paulo: Konrad Adenauer/Universidade Estadual Paulista Júlio de Mesquita Filho, pp. 345-371.

Movimento Endireita Brasil. 2012. Estatuto do Movimento Endireita Brasil. Fortaleza.

Nicolau, Jairo \& Peixoto, Vitor. 2007. "Uma disputa em três tempos: uma análise das bases municipais das eleições presidenciais de 2006." Anais do 31ㅡㅡㄹ contro da Anpocs, Caxambu.

Nicolau, Jairo. 2012. Sistemas Eleitorais. Rio de Janeiro: Editora FGV.

Norris, Pippa. 1999. Critical citizens: global support for democratic governance. Oxford: Oxford University Press.

Oliveira, Raquel. 2007. "Passeata pelas vítimas reúne 6.000 sob frio de $7^{\circ} \mathrm{C}$ ". Folha de São Paulo Online. Disponível em: <www1.folha.uol.com.br/fsp/cotidian/ff3007200713.htm> Publicado em 30 de Jul. 2007. Acesso em: 22 de set. 2017 
Paiva, Denise \& Tarouco, Gabriela. 2011. "Voto e identificação partidária: os partidos brasileiros e a preferência dos eleitores". Opinião Pública, vol. 17, no 2, pp.426-451.

Paiva, Denise; Krause, Silvana; Lameirão, Adriana. 2016. "O eleitor antipetista: partidarismo e avaliação retrospectiva". Opinião Pública, v. 22, n. 3, pp. 638-674.

Panizza, Fernando. 2005. "Unarmed utopia revisited: the resurgence of left-of-centre politics in Latin America”. Political Studies, v. 53, n. 4, pp. $716-734$.

Poletti, Luma. 2017. "Ministro da Educação recebe Alexandre Frota e grupo próimpeachment". Congresso em foco. Disponível em: $<$ http://congressoemfoco.uol.com.br/noticias/ministro-da-educacao-recebe-alexandre-frota-egrupo-pro-impeachment/>. Acesso em: nov. 2017.

Putnam, Robert. 2003. El declive del capital social. Barcelona: Galaxia Gutenberg.

Putnam, Robert. 2002. Solo en la bolera: Colapso y resurgimiento de la comunidade norteamericana. Barcelona: Galaxia Gutenberg, 2002.

Redação Época. 2016. As manifestações de 13 de março em todo o Brasil. Disponível em: <http://epoca.globo.com/tempo/noticia/2016/03/manifestacoes-de-13-de-marco-em-todo-obrasil-acompanhe.html>. Acesso em: nov. 2017

Rennó, Lucio. 2007. "Escândalos e voto: as eleições presidenciais brasileiras de 2006". Revista Opinião Pública. Campinas, v. 13, n², pp. 260-282.

Ribeiro, Ednaldo. 2011. Valores pós-materialistas e cultura política no Brasil. Maringá: Universidade Estadual de Maringá.

Rodrigues, Leôncio Martins. 2002. Partidos, ideologia e composição social: Um estudo das bancadas partidárias na Câmara dos Deputados. São Paulo: Universidade de São Paulo.

Singer, André. 2012. Os sentidos do lulismo: reforma gradual e pacto conservador. São Paulo: Companhia das Letras.

Tatagiba, Luciana; Trindade, Thiago; Teixeira, Ana Claudia. 2015. "Protestos à Direita no Brasil”. In: Cruz, Sebastião; Kaysel, André; Codas, Gustavo (Orgs.). Direita Volver! O retorno da direita e o ciclo político brasileiro. São Paulo: Editora Perseu Abramo, pp. 197-213.

Telles, Helcimara. 2012. "A construção do terceiro mandato de Lula da Silva: a transferência de prestígio nas campanhas presidenciais brasileiras de 2010". In: Congresso Latinoamericano de Opinión Publica. Anais.

Telles, Helcimara. 2003. "O PT e as eleições: da liderança pragmática à base programática". In: Telles, H.; Lucas, J. (Orgs). Das ruas às urnas: partidos e eleições no Brasil contemporâneo. Caxias do Sul: Universidade de Caxias do Sul, pp. 15-47.

Torcal, Mariano \& Monteiro, José Ramon. 2006. Political disaffection in contemporary democracies: social capital, institutions and politics. London: Routedge.

Uribe, Gustavo; Lima, Gabriela; Lima, Galeno. 2014. "Manifestações contra a Dilma reúne 2.500 pessoas em São Paulo". Folha de São Paulo Online. Disponível em: < http://www1.folha.uol.com.br/poder/2014/11/1542047-ato-em-sao-paulo-pede- 
impeachment-de-dilma-e-intervencao-militar.shtml> Publicado em: 01 nov. 2014. Acesso em: nov. 2017.

Van Biezen, Ingrid. 2014. The End of Party Democracy as we know it? A Tribute to Peter Mair. Irish Political Studies, v. 29, 2, p. 177-193, 2014.

Van Biezen, Ingrid; Mair, Peter; Poguntke, Thomas. 2012. "Going, going...gone? The decline of party membership in contemporaray Europe". European Journal of Political Research, v. 51, $\mathrm{n}^{\circ}$ 1, pp. 24-56.

Veiga, Luciana. 2007. "Os partidos brasileiros na perspectiva dos eleitores: mudanças e continuidades na identificação partidária e na avaliação das principais legendas após 2002". Opinião Pública, vol. 13, oㅡ 2, pp.340-365.

Veiga, Luciana. 2011. "O partidarismo no Brasil (2002/2010)". Revista Opinião Pública, v. 17, n 2, pp. 400-424.

Venturini, Gustavo. 2010. "PT 30 anos: crescimento e mudanças na preferência partidária. Impacto nas eleições de 2010". Revista Perseu: História, Memória e Política, ano 4, n5, pp. 196-214, 2010.

Wenman, Mark. 2013. Agonistic democracy: constituent power in the era of globalization. Cambridge: Cambridge University Press.

Weyland, Kurt. 2009. "The Rise of Latin America's Two Lefts Insights". Comparative Politics, v. $41, n^{\circ} 2$, pp. 145-164.

Whitaker, Paulo. 2015. "Cidades registram panelaço durante programa do PT com Lula e Dilma". G1. Disponível em: http://g1.globo.com/politica/noticia/2015/08/cidades-registramprotestos-durante-programa-do-pt-com-dilma-e-lula.html. Publicado em: 06. Ago. 2015. Acesso em: nov. 2017.

Zucco Junior, Cesar. 2014. "Estabilidad sin raíces: institucionalización de sistemas de partidos en Brasil”. In: Torcal, Mariano (ed.). Los problemas de la institucionalización de los sistemas de partidos en América Latina. Madrid/Buenos Aires: Anthropos/Siglo XXI. 